\title{
Silêncio perfumado
}

\section{Ana Pereira}

Cada teatro tem um cheiro. Cada teatro é uma pessoa, com vida, memórias, passado. No início, a fotografia cumpria para mim o papel da memória a que eu não conseguia chegar, do passado que era o meu. Depois, a fotografia tornou-se uma forma de aceder ao mundo. De poder ver e sentir as vidas que não a minha. Mais tarde, a fotografia tornou-se o quotidiano e já sei que todos os quotidianos se ressentem do peso do que não é novo.

Voltando ao teatro. Quando a Sinais de cena (obrigada!) me propôs organizar este portfolio, comecei a procurar as imagens e, ao chegar ao arquivo em negativo, percebi que faço fotografia de cena há quase 10 anos.

\section{0 início}

Os bastidores representam para mim um mistério. Alice que espreita para lá do espelho. Eu, que venho da multidão, subo as escadas e ando por dentro do palco, a ver as pessoas que circulam por lá - no escuro que afinal tem muitas luzes - e como fazem aquelas pessoas tudo aquilo que fazem, como se relacionam no silêncio interior do espectáculo de forma a que tudo resulte.

A fotografia de cena, a de palco, por exigir um maior distanciamento entre mim e o que eu fotografo, condiciona mais o meu trabalho: o sujeito fotografado existe para além da minha vontade e de toda a minha acção. Considero a fotografia de cena uma forma de fotografia documental em estado puro, por sofrer uma intervenção mínima do fotógrafo sobre o tema fotografado.

0 fotógrafo faz as melhores opções técnicas e de composição para chegar ao resultado visualmente mais interessante, mas as imagens, essas, devem em última análise fazer jus à visão do encenador e ao trabalho de todos os criativos envolvidos.

\section{0 trajecto}

0 primeiro contacto fotográfico com o teatro foi através do espectáculo Caleidoscópio, do Teatro Bruto, numa coprodução com o Teatro Nacional S. João (TNSJ), em 2000.

Posteriormente, através das imagens dos bastidores desta peça, fui convidada a participar num projecto fotográfico muito interessante. Em ano de Porto Capital Europeia da Cultura, um grupo de fotógrafos liderado pelo João Tuna e composto por mim, a Rita Burmester, a Margarida Ribeiro e o Henrique Delgado, iria fotografar o festival PoNTI, que se estendeu durante todo o ano de 2001, para um livro com design do atelier João Nunes, publicado pelo Teatro Nacional S. João, então sob a direcção de José Wallenstein. A proposta consistia em efectuar uma cobertura total e exaustiva do festival, fotografia de cena e bastidores, sendo essencial tornar-se visivel no trabalho fotográfico dos bastidores as diferentes linguagens dos vários fotógrafos.

Entre 2002 e 2003, continuei a fotografar a programação do Teatro Nacional S. João e posteriormente também a do Auditório Carlos Alberto (ANCA). Para além da colaboração com outras companhias, iniciei em 2004 uma colaboração com a ASSéDIO, que se mantém até hoje.

Ao seleccionar as imagens para este portefólio, percebi como a fotografia de cena é essencialmente o registo do trabalho do actor.

\section{0 corpo e o rosto do actor}

Nós, os que estamos aqui deste lado, revemo-nos naqueles homens e mulheres, nas possibilidades que transfiguram como suas, do melhor e do pior que sabemos existir e de todas as opções intermédias.

Às vezes, quando estou ali, segura, no escuro, atrás da lente da minha máquina, penso como será entrar e sair 
daquelas pessoas que vão habitando? Será difícil, deixarà marcas?

Outras vezes vejo-os só a crescer, alimentados pela luz e pelo ruído surdo dos nossos olhos que os acompanham para qualquer lado do palco que nunca se perde. E depois a voltarem outra vez ao tamanho que é o nosso.

\section{0 teatro e a tela}

A fotografia de cena levou-me em 2006, com o espectáculo Alter ego, do Teatro Bruto, para fora do espaço do teatro, dando início a um projecto pessoal sobre os cinemas abandonados da cidade do Porto, que se prolongou até 2008 e que intitulei $A$ tela de uma história que não se acende.
Para finalizar este meu ainda pequeno trajecto, refiro a minha colaboração desde 2007 com a Academia Contemporânea do Espectáculo (ACE). Faço referência a esta colaboração, porque ao fotografar os projectos cénicos desta escola, sinto-me a regressar ao princípio, à formação de uma nova geração de actores e criativos teatrais E eles estão ali, naquele momento primeiro, onde existe apenas a paixão do palco e das palavras e aquele silêncio perfumado que antecede sempre todos os inícios...

\section{Companhias, pessoas e teatros, por ordem alfabética} ACE, Ana Luena, ANCA, ASSéDIO, Casa da Música, Companhia Olga Roriz, Cornucópia, Ensemble, João Cardoso, João Nunes, João Tuna, José Wallenstein, Lilástico, Né Barros, Rosa Quiroga, Teatro Bruto, Teatro Helena Sá e Costa, Teatro de Marionetas do Porto, TNSJ...

\section{Legendas}

1 > 0 colar, de Sophia de Mello Breyner Andresen,
enc. Luis Miguel Cintra, Teatro da Cornucópia / TNSJ,
2002 (Rita Durão).
2 > A mandrógora, de Maquiavel,
enc. João Paulo Costa, ACE (Academia Contemporânea
do Espectáculo), prova do 2.0 ano, 2008.
3 > Ladrões de almas,
a partir de Lugar lugares de Herberto Hélder,
enc. Joana Providência,
Teatro do Bolhão / Academia Contemporânea do
Espectáculo, 2008
(António Júlio).
4 > No fundo no fundo, de Jacinto Lucas Pires,
enc. Marcos Barbosa, Lilástico / TNSJ, 2002
(Ana Rita de Jesus e Tiago Rosa).
5 > Terminus, de Mark O'Rowe,
enc. João Cardoso, ASSéDIO, 2008
(Micaela Cardoso).

(Micaela Cardoso).

\section{6 > Um número, de Caryl Churchill, enc. João Pedro Vaz, ASSéDIO, 2005 (João Cardoso e João Pedro Vaz).}

7 > Vou mudar a cozinha, de Ondjaki, enc. Ana Luena, Teatro Bruto, 2007 (Sandra Salomé).

$8>$ A testemunha, de Cecilia Parkett enc. João Cardoso, ASSéDIO, 2004 (Rosa Quiroga).

$9>$ Gertrud, de Einar Schleef, enc. Thomas Bischoff, Düsseldorfer Schauspielhaus, PoNTI 2004 (Catherine Janke e Anke Hartwig).

$10>$ A resistivel ascensão de Arturo Ui, de Bertolt Brecht. enc. Kuniaki Ida, ACE / Teatro do Bolhão / TNSJ, 2003 (Mnuela Paulo e João Paulo Costa).

11 > Contra a parede + Menos emergências, de Martin Crimp, enc. João Cardoso, ASSéDIO, 2004 (João Cardoso, Paulo Freixinho e Ligia Roque).

\section{$12>$ Não destruam os mal-me-queres, direcção e texto de Olga Roriz,} Companhia Olga Roriz / Fundação das Descobertas, 2002.

$13>$ Alter ego, de Artur Serra Araújo,

enc. Ana Luena, Teatro Bruto, 2006

(Mário Santos, Luciano Amarelo,

Marta Gorgulho e Pedro Mendonça).

14 > 0 lobo Diogo e o mosquito Valentim, de Eurico Carrapatoso, Teatro de Marionetas do Porto / Casa da Música / Orquestra Nacional do Porto, 2006 (Sérgio Rolo, ao centro).

15 > Pó (2. parte do espectáculo Ícones), a partir de Romeu e Julieta, de William Shakespeare, direç̧ão e coreografia de Isabel Barros, Balleteatro Companhia / Eira / Teatro Nacional S. João, 2002 (Paulo Moura Lopes, ao fundo).

16 | $17 \mid 18$ > A hora em que não sabiamos nada uns dos outros, de Peter Handke, enc. José Wallenstein, Teatro Nacional S. João, 2001 (bastidores). 


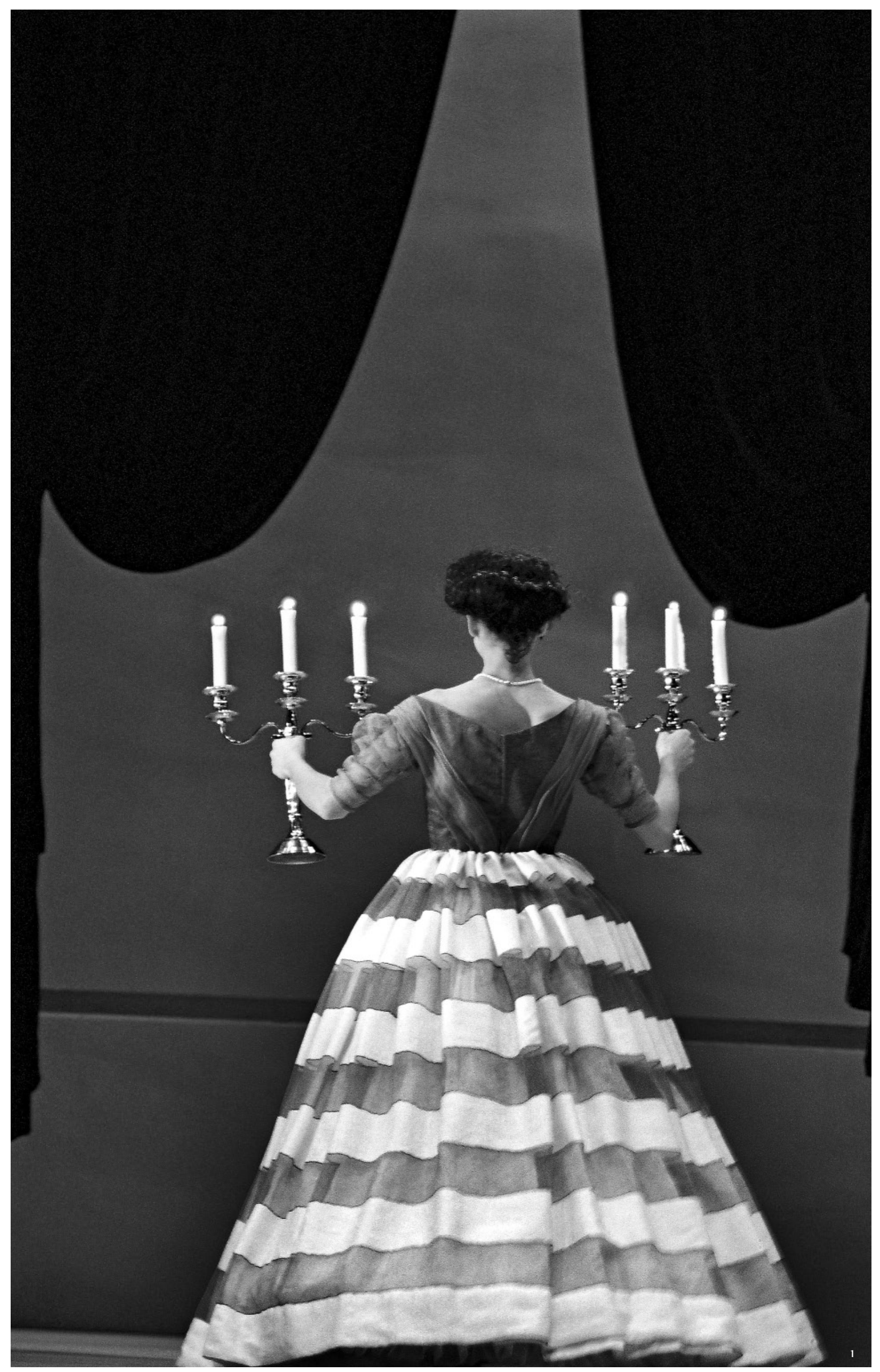




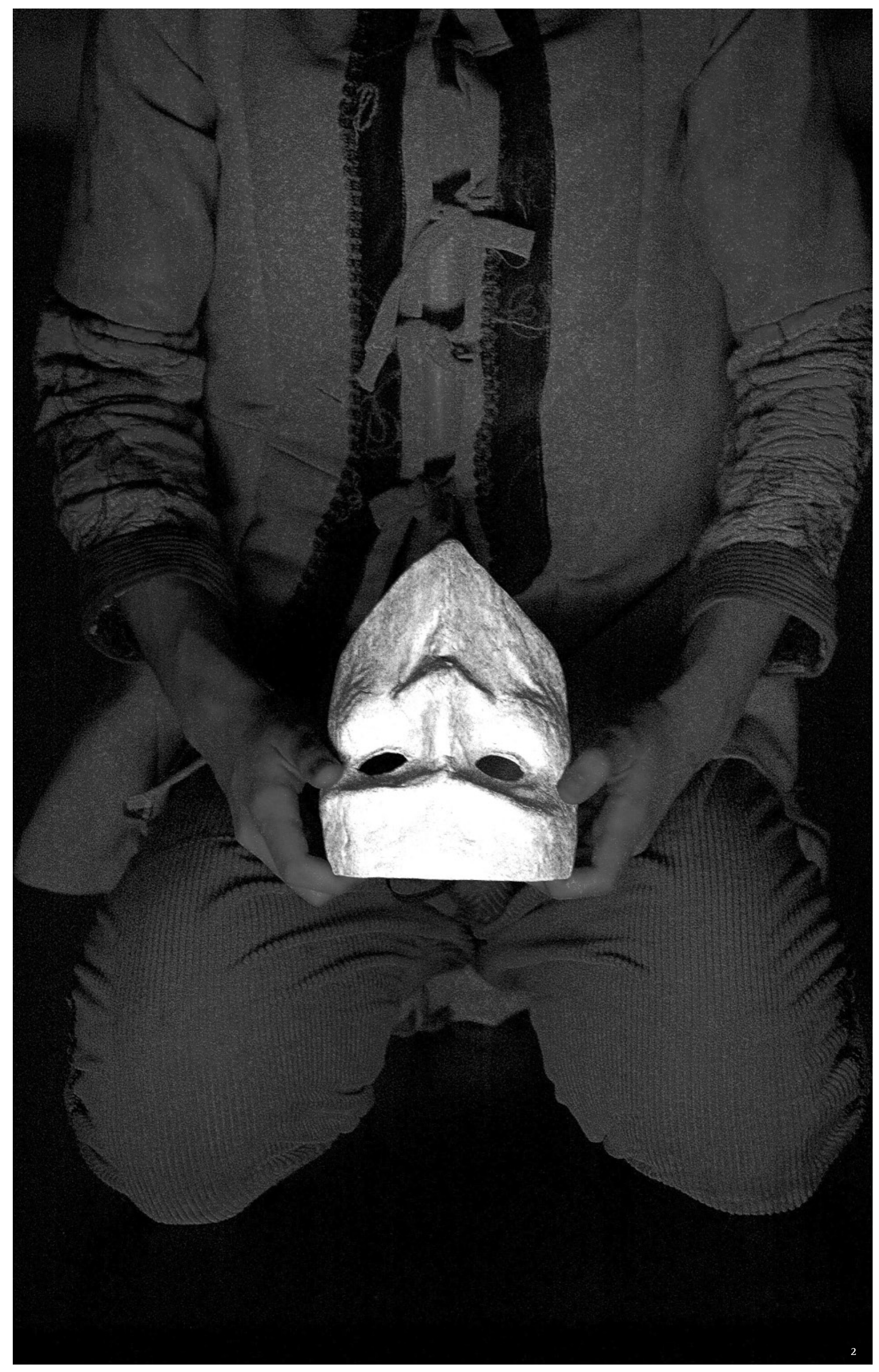




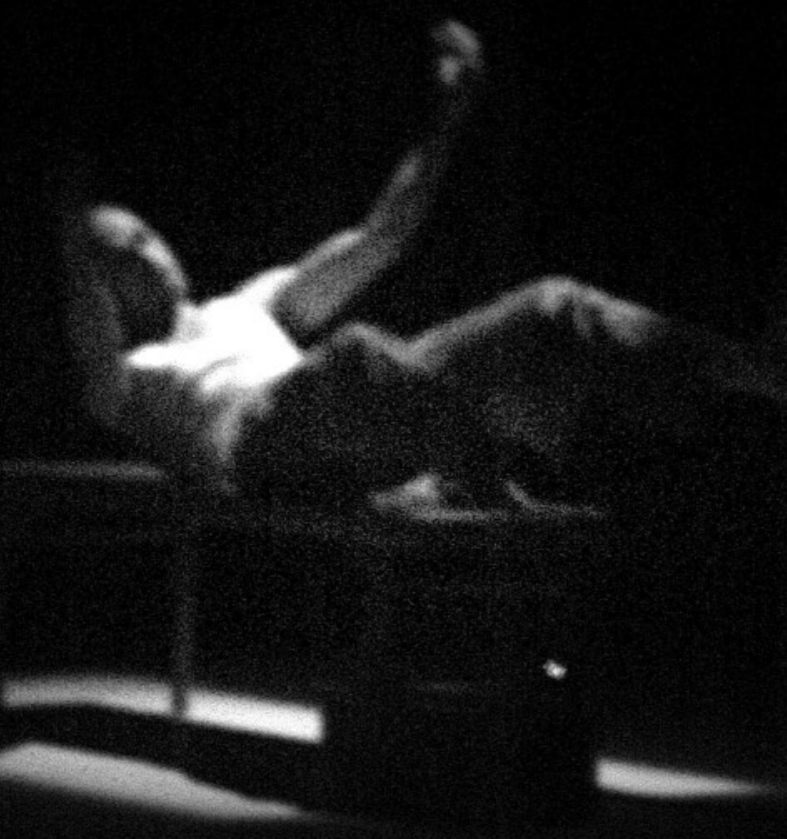




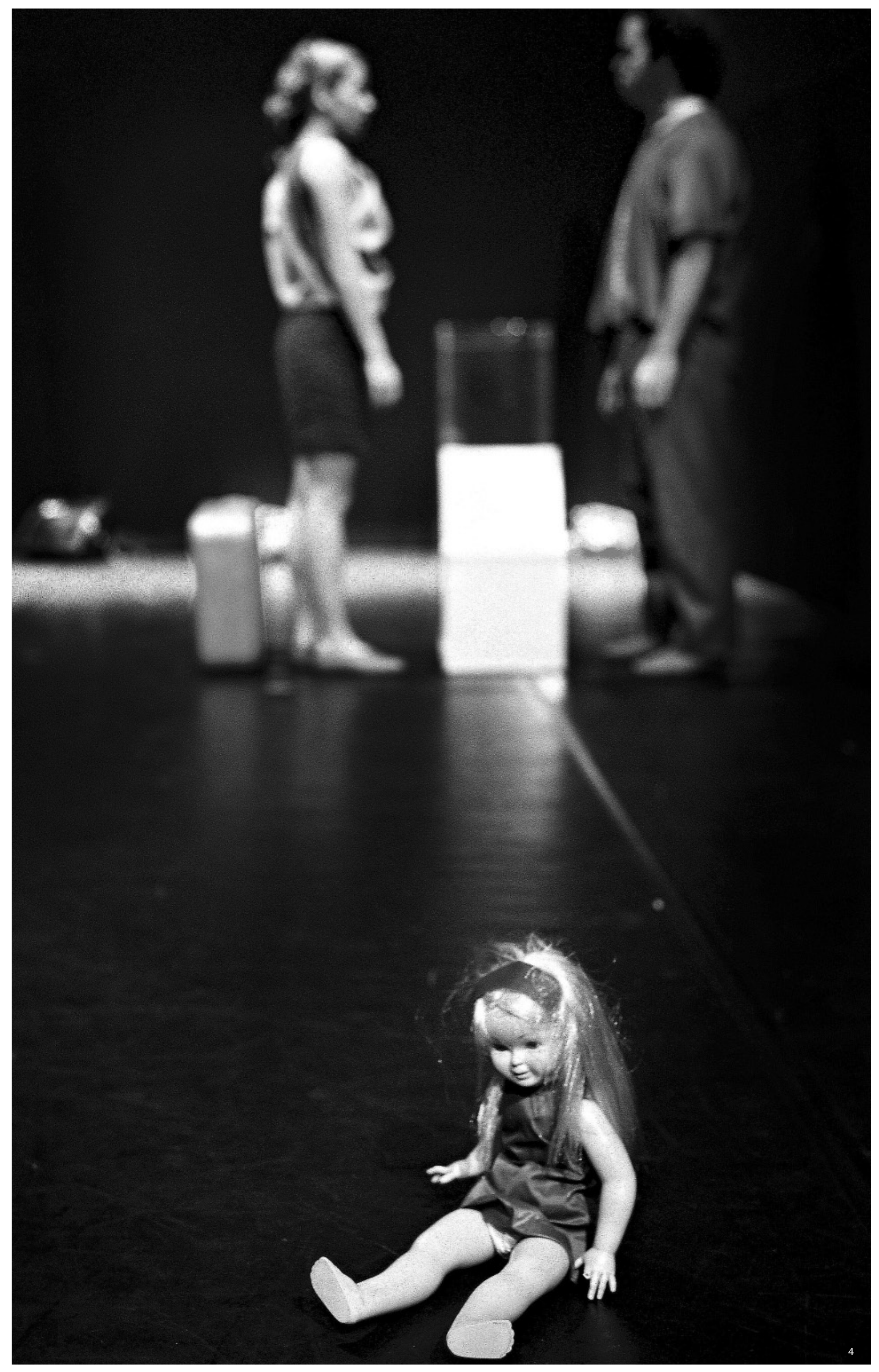



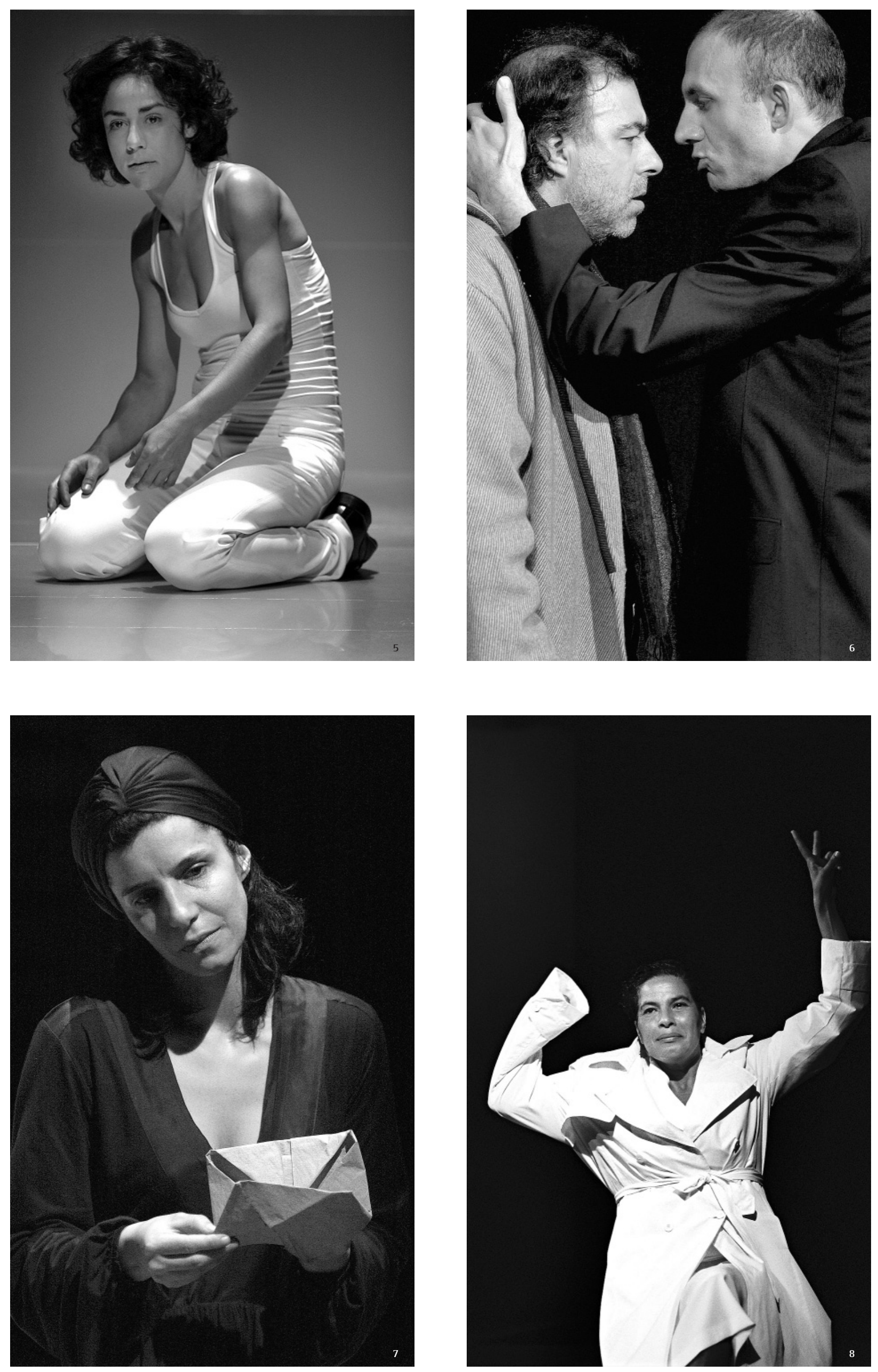

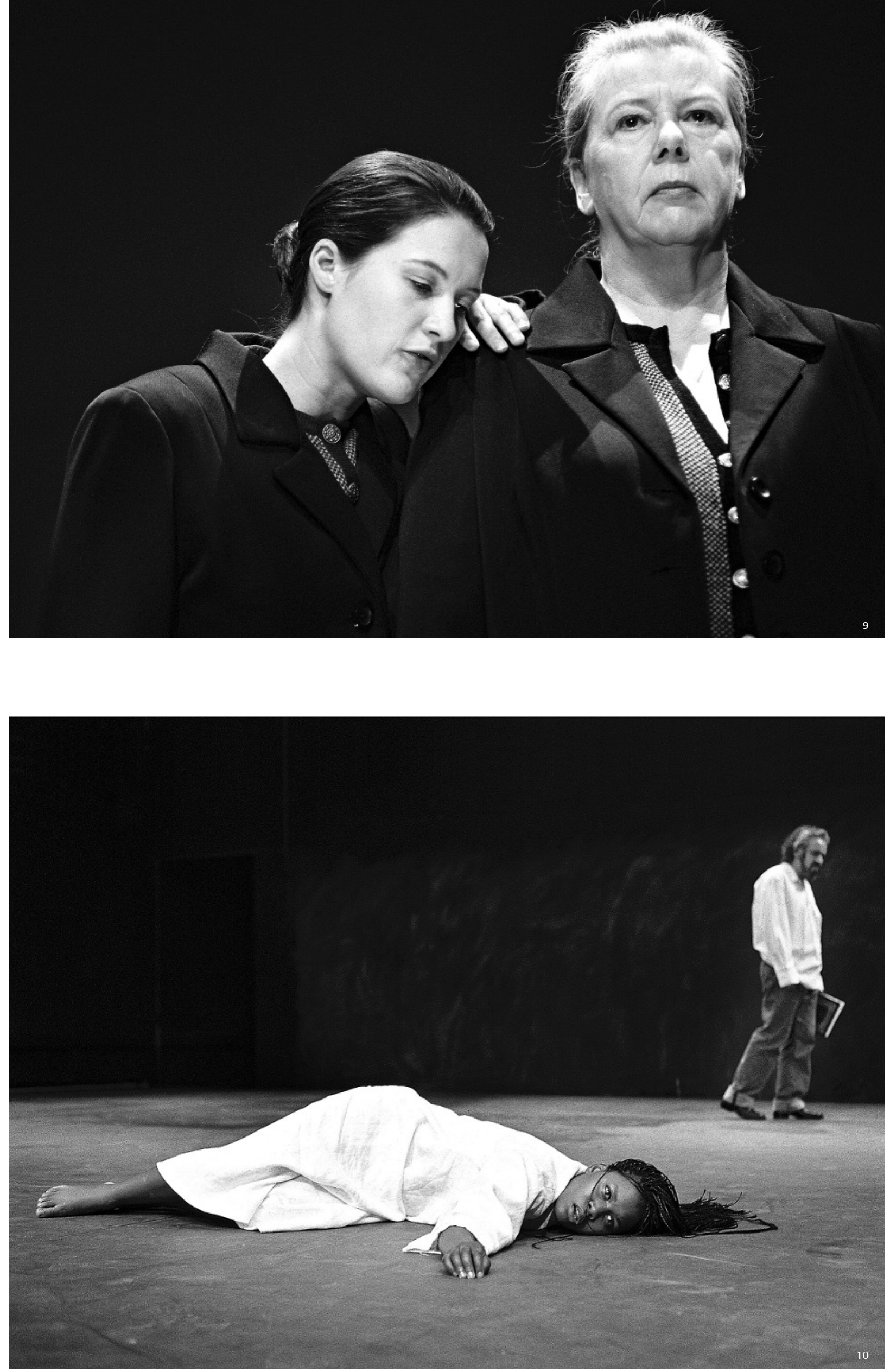

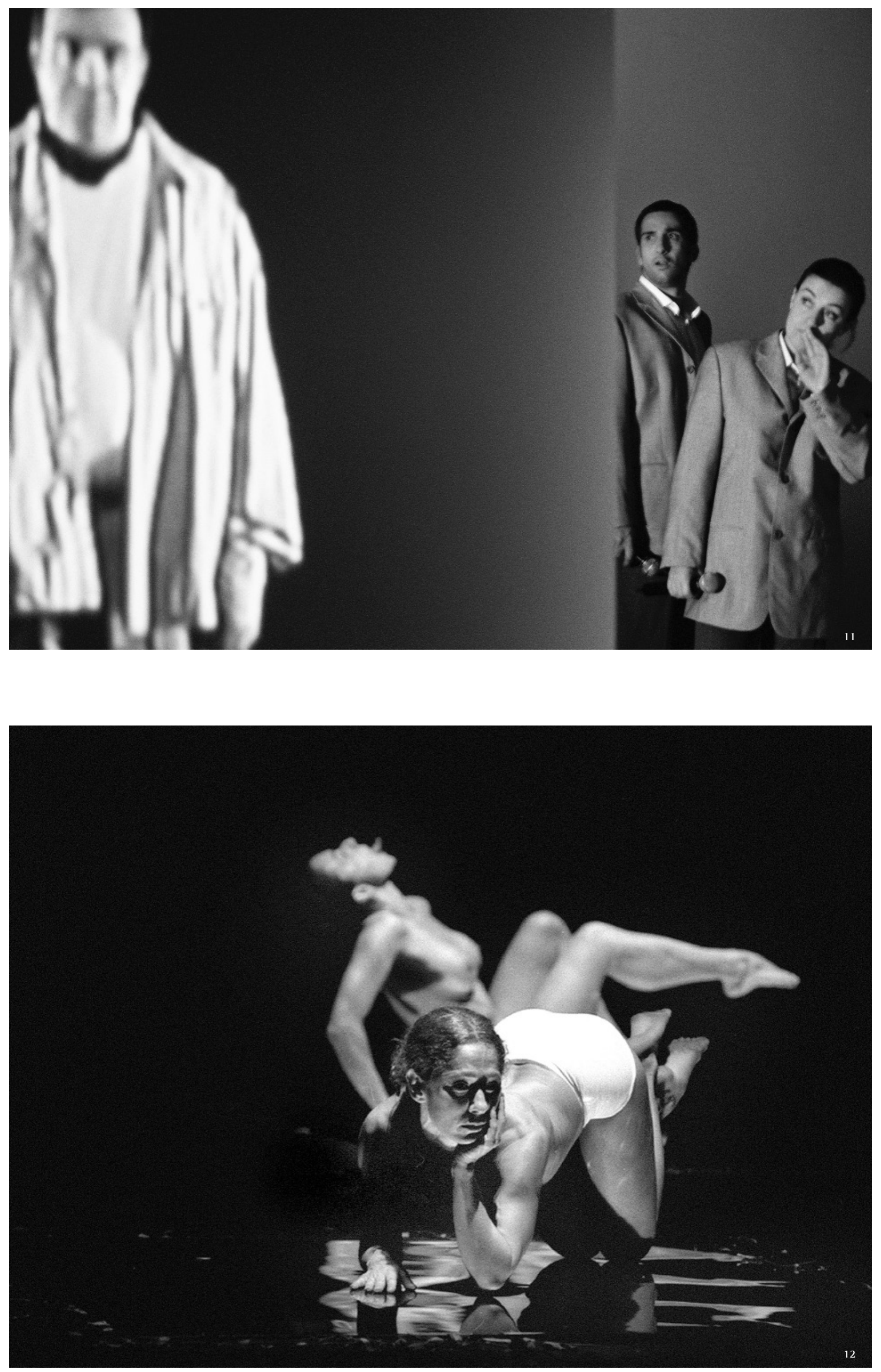

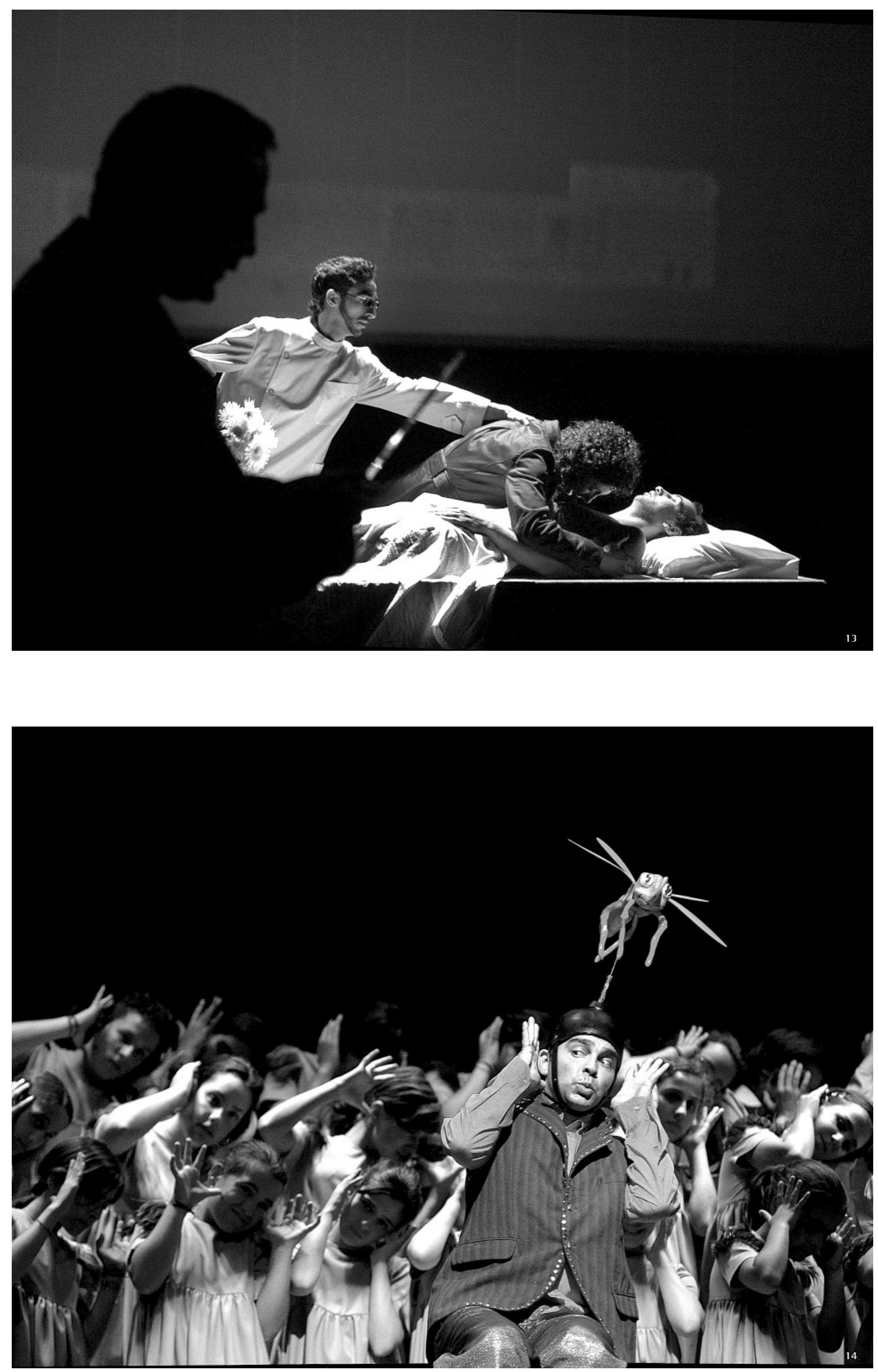

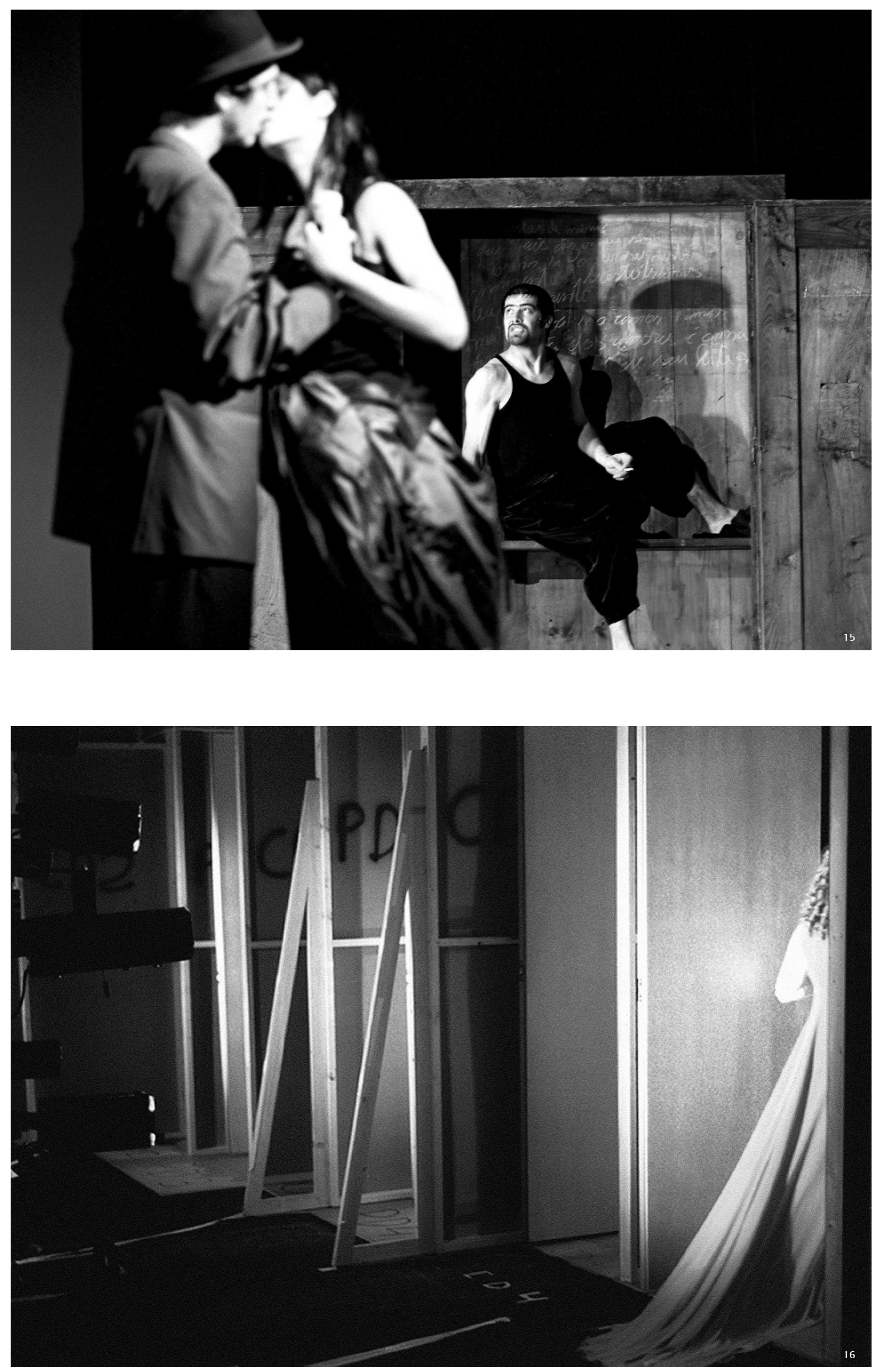

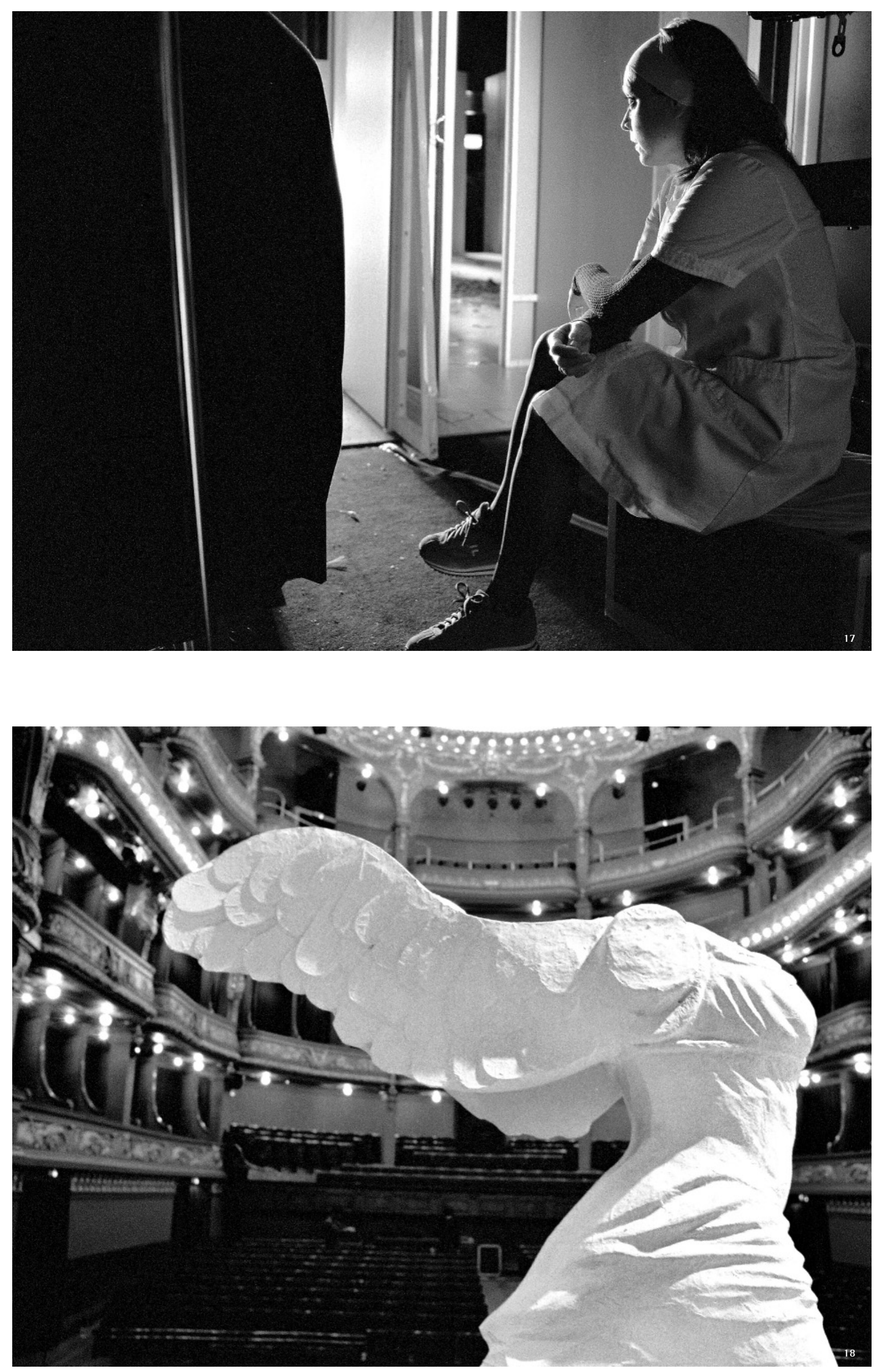